\title{
Development of a bioaction complex for the onychodystrophy treatment
}

\author{
Evgenia Gurkovskaya ${ }^{1}$, Anna Bolotova ${ }^{2}$, Natalia Savchenko ${ }^{1}$, Alexandr Petrov ${ }^{2}$, and \\ Alexandra Shubina ${ }^{1}$ \\ ${ }^{1}$ Ural state medical university, Department of Dermatovenereology and Life Safety, 620028, Repin \\ Str., 3, Yekaterinburg, Russian Federation \\ ${ }^{2}$ Ural state medical university, Department of Pharmacy and Chemistry, 620028, 3, Repin Str., \\ Yekaterinburg, Russian Federation
}

\begin{abstract}
This article is devoted to the problem of onychodystrophy treatment. The purpose of the study was to develop a bioactive complex for the external treatment of onychodystrophies. We conducted a prospective cohort study to determine the emotional status and life quality of patients with onychodystrophies. The optimal composition and technology for producing a complex for the onychodystrophy treatment was determined in vitro. We made a literature review using the PubMed, eLibrary, Scopus, Web of Science search engines. The structure of onychodystrophies in patients of the study group was determined, clinical forms such as leukonychia, paronychia, onycholysis were diagnosed the most frequently. A significant decrease in life quality was found in $86.8 \%$ of patients. A new method of onychodystrophies treatment using the innovative medical complex, which includes an emulsion for external use and camouflage nail polish is proposed. The developed bioactive complex for patients with onychodystrophy will contribute to the rapid regeneration of the changed nail plate due to improved microcirculation and trophic innervation. More viscous and thick consistency physiological colour nail polish which does not require polymerization, will create a visual effect of a healthy nail plate, which will improve the life quality of patients with onychodystrophy.
\end{abstract}

\section{Introduction}

According to statistics, $40 \%$ - $45 \%$ of the world's population have nail diseases of varying severity, and $40 \%-50 \%$ of cases are onychodystrophy $[1,2,3]$. Onychidystrophy is a general term that includes pathological changes that occur in nail unit due to endogenous and exogenous factors associated with aboitriohy of the nail matrix, the nail plate, the nail bed and the nail folds $[2,4,5]$. Onychidystrophy can be caused by various conditions, such as chronic somatic pathology, metabolic disorders, micronutrient deficiency, mechanical damage to the nail plate (trauma, improper processing during manicure), chemical effects (toxic effect of nail polisheses, polymerization products of long-term coatings $[6,7,8]$. 
Depending on the etiology, damaging factors can be divided into 4 groups: local pathological processes, general infectious processes, diseases of internal organs and skin diseases [4]. M.M. Simoes Mendonca et al (2015) describe the clinical cases of severe allergic dermatitis due to acrylic manicure, UV-curing gel nail polishes. Moreover, in one patient, onychodystrophy was represented by total onycholysis of the nail plates, and in the other patient, subungual hyperkeratosis imitated psoriasis and the process was resistant for treatment for a long time [9]. Often, damage to the nail plates is a symptom of severe dermatological diseases such as T-cell lymphoma, lupus erythematosus, psoriasis, focal alopecia, lichen planus and may precede the appearance of the main symptoms of the disease $[10,11,12,13]$. Thus, Prayogo R.L. et al (2020) describe a 9-month-old boy with longitudinal stripes, onychodystrophy and paronychia on the nail plates of the hands and feet. Nail damage was the initial manifestation of multisystem Langerhans cell histiocytosis [14]. G. Moreno-Coutiño et al (2016) in their study consider the occurrence of onychodystrophy in elderly patients as a possible marker of peripheral artery disease, being an important factor in early diagnosis [15].

According to domestic and foreign authors, deformation and discoloration of the nail plates leads to a significant decrease in the life quality due to aesthetic discomfort, social maladaptation during communication in everyday life [10, 16, 17].

Various topical and systemic therapies have been performed to investigate their potential beneficial role in disorders of the nail. It is necessary for the onychodystrophies treatment to eliminate the trigger factor, and provide an integrated approach, including systemic and topical therapy. The main purpose in the treatment is the impact on the nail matrix, the place, where stromal cells multiply, so vascular preparations, vitamins and mineral complexes can be used for systemic therapy. In the onychodystrophies treatment associated with skin diseases, antihistamines, glucocorticosteroids, retinoids and others can be prescribed $[2,18]$. A feature of the onychodystrophies treatment is the lack of a wide range of choice in effective external medicines aimed at strengthening the nail plate, stimulating the matrix and enhancing regeneration, as well as correcting deformations and colors of the affected nail plates $[18,19,20]$.

Thus, the purpose of the study was to develop an effective bioactive complex for the external treatment of onychodystrophies.

\section{Materials and Methods}

The study was conducted on the departments of Dermatovenereology and Life Safety and the Department of Pharmacy and Chemistry of the Ural State Medical University. The study included a sociological method for assessing the emotional and psychological status of patients with onychodystrophies using the Dermatology Life Quality Index (DLQI), and developing a complex for the external treatment of onychodystrophies. The patients enrolled in the study applied for primary specialized medical care to a dermatovenerologist. From patients informed consent was obtained.

The present study included 76 patients with local pathological processes in the nail plate, 33 of them $(43.4 \%)$ were male and $43(56.5 \%)$ were female. The median age was 29 years, the interquartile range: 19-39. The diagnosis of onychodystrophy was established on the basis of the clinical features of the disease, pathology of internal organs, and dermatological diseases in the absence of general infectious diseases. To exclude a possible fungal infection of the nails, all patients underwent microscopic and mycological examination. To assess the severity of damage to the nail plate, the severity index of nail dystrophy (Naildex) was used [17]. All nail plates were evaluated by the presence of infection, onycholysis, excessive growth, subungual hyperkeratosis, the percentage of damage to the nail plate and the area of damage, the result was evaluated from 0 (no 
symptoms) to 1 (total damage to the nail plates). The DLQI score was evaluated in points before using of the treatment complex, repeatedly after the end of treatment and in 3 months.

Further, an emulsion for the external treatment of onychodystrophies was developed, and the technology for producing camouflage nail polish was modeled in the laboratory of the Department of Pharmacy and Chemistry of the Ural State Medical University. To obtain laboratory samples of the developed compositions, next auxiliary substances were used: oil (CJSC Ekolab - Russia), tween-80 emulsifier (LLC Chemical Reagents, Russia), purified water (SP 14), active components according to the requirements of regulatory documents. To simulate the nail polish production technology in the laboratory, ethyl acetate, butyl acetate, sterialconium bentonite, cellulose acetate butyrate, styrene-acrylate copolymer, adipic acid, neopentyl glycol, trimellitic anhydride polymer, pigment were used according to manufacturer's instructions.

A literature review of domestic and foreign sources using the search engines PubMed, eLibrary, Scopus, Web of Science was made. Statistical processing of the obtained data was carried out using the Microsoft Excel 2000 and STATISTICA-13 packages. The median, 1 and 3 quartiles were calculated. Results were regarded as statistically significant, in case $\mathrm{P}<0.05$.

\section{Results and Discussion}

Among the study group, leukonychia was found in $32(42.1 \%)$ patients; paronychia was observed in $15(19.7 \%)$ patients, onycholysis - in $13(17.1 \%)$ patients (Figure 1), 16 $(21.1 \%)$ patients were diagnosed with more rare clinical forms of onychopathy, such as onychoschizis (Figure 2) and onychomadesis.

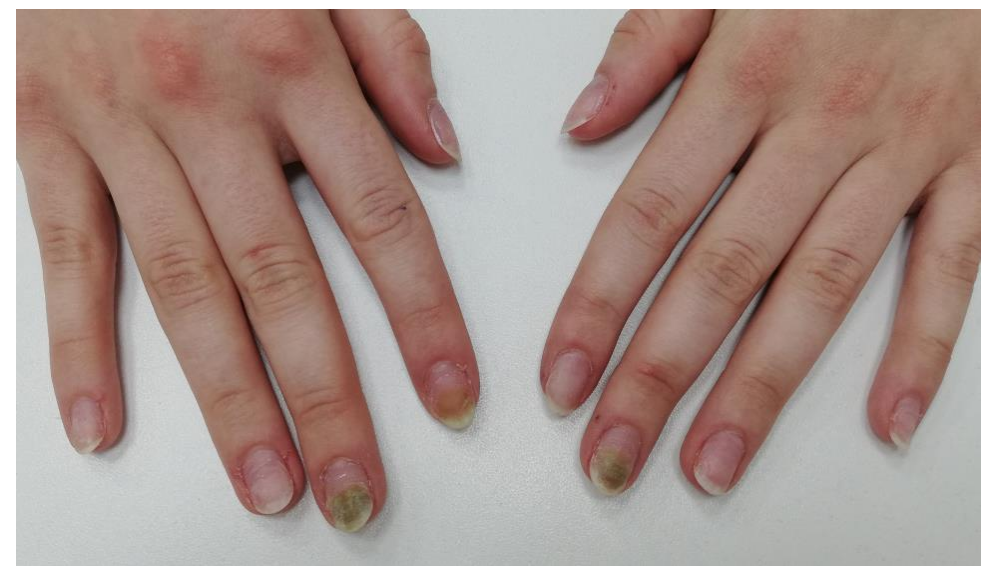

Fig. 1. Woman, 25 y.o. Onycholysis after the long-term use of sculptured acrylic nails. 


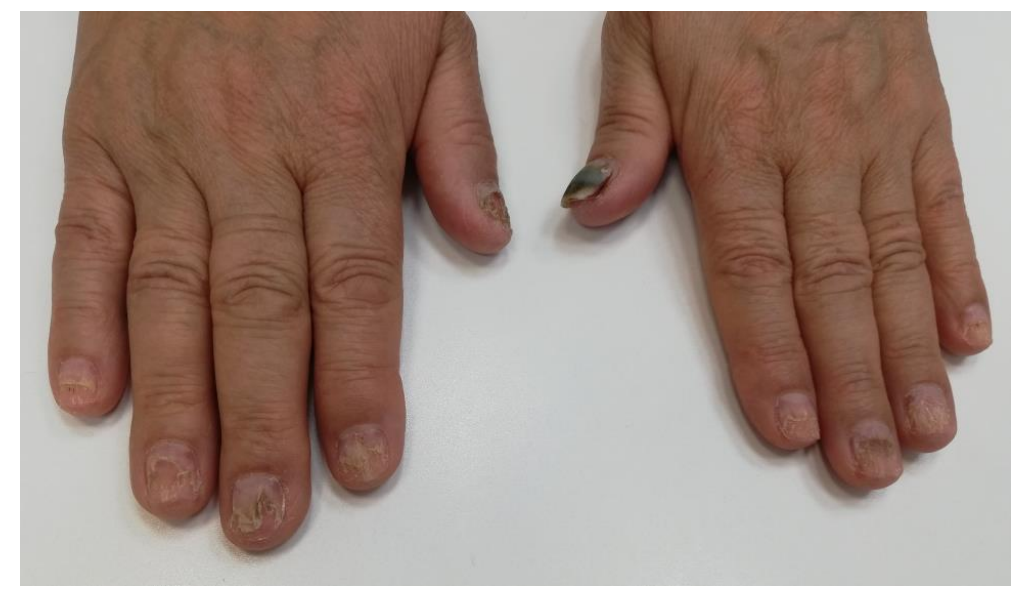

Fig. 2. Woman, 46 y.o. Onychoschizis of the nail plate of the hands.

As for assessing the severity of dystrophy index in both women and men, patients with moderate severity prevailed, which was equal to damage of 2 or 3 nails per 1 hand or foot. The Naildex ranged from 0.41 to 0.65 points (Table 1 ).

Table 1. The severity in patients with onychodystrophy $(n=76)$.

\begin{tabular}{|l|c|c|c|c|c|c|}
\hline \multirow{2}{*}{ The severity of dystrophy } & \multicolumn{2}{|c|}{ Male } & \multicolumn{2}{c|}{ Female } & \multicolumn{2}{c|}{ Total } \\
\cline { 2 - 8 } & $\boldsymbol{n}$ & $\boldsymbol{\%}$ & $\boldsymbol{n}$ & $\boldsymbol{\%}$ & $\boldsymbol{n}$ & $\boldsymbol{\%}$ \\
\hline Mild & 5 & 6,6 & 6 & 7,9 & 11 & 14,5 \\
\hline Medium & 23 & 30,2 & 35 & 46,1 & 58 & 76,3 \\
\hline Severe & 5 & 6,6 & 2 & 2,6 & 7 & 9,2 \\
\hline
\end{tabular}

As a result of the assessment of emotional-psychological status of patients with affected nail plates before using the treatment complex, a significant effect of the skin process on a decrease in the life quality was revealed. Thus, $51(86.8 \%)$ patients noted that alterated nails, soreness, and other symptoms significantly affect the physical and mental component of their life quality, while in women with onychopathies, a decrease in the life quality was significantly more frequent (table 2 ).

Table 2. DLQI score (before treatment) in patients with onychodystrophies $(n=76)$.

\begin{tabular}{|l|c|c|c|c|}
\hline \multirow{2}{*}{ DLQI score before treatment } & \multicolumn{2}{|c|}{ Male } & \multicolumn{2}{c|}{ Female } \\
\cline { 2 - 5 } & $\boldsymbol{n}$ & $\boldsymbol{\%}$ & $\boldsymbol{n}$ & $\boldsymbol{\%}$ \\
\hline Very much & 9 & 11,8 & 22 & 28,9 \\
\hline A lot & 16 & 21,1 & 19 & 25,0 \\
\hline A little & 6 & 7,9 & 2 & 2,6 \\
\hline Not at all & 2 & 2,6 & 0 & 0,0 \\
\hline
\end{tabular}

Also we found that 48 patients $(63.1 \%)$ feel uncomfortable when interacting with other people, more than a half of all participants pay attention to the nail plates of other person during the communication, and one person in three noted negative emotions at the site of alterated nails, and one person in two noted compassion for the talk partner.

In the study sample, $56(73.6 \%)$ patients suffered from onychodystrophy for 1 month, in $13(17.2 \%)$ changes in the nail plates occurred within 3 months, $7(9.2 \%)$ patients were admitted after 6 months. At the same time, only $17(12.9 \%)$ patients apply self-treatment using topical antimycotic agents. 
We proposed to develop the composition and technology of the complex for the onychodystrophy treatment, which includes an emulsion for inunction in the periungual roller and camouflage nail polish. It should be noted that the combination of two topical agents will allow to manage the problem of onychodystrophy in a complex way, by stimulating the growth of the nail plate due to the active components of the emulsion (drugs that improve microcirculation, trophic innervation, stimulating tissue regeneration, vitamins). The second part of the complex is a camouflage coating for the nail plates, which will fulfill an exclusively cosmetic role and aimed at hiding irregularities and creating a visual effect of a healthy nail. The incorporation of active components into the nail polish composition is impractical, since the penetrating ability and bioavailability of drugs through the nail plate is insignificant.

A universal composition was developed for the nail polish. The fundamental difference is that nail polish is initially positioned and developed as special camouflage covering and does not contain components, whose penetration through the nail plate is impossible, unlike analogues In contrast to the wide range of decorative coatings for nails, camouflage nail polish will have more viscous and thick consistency, and the colour of a healthy nail plate, moreover it will not contain components that are highly toxic. In order to provide additional protection against injuries during coating removal, coarse pigments and polymers will be absent from the nail polish. The created prototype nail polish has high adhesiveness and viscosity, which allows to hide irregularities and apply it to the nail plate as little as possible. During the study, the camouflage nail polish production technology was also simulated using the IKA RET basic magnetic stirrer. Pigments and dyes were added into the previously obtained colorless base for nail polish industrially by varying their ratio and quantity. Stirring was carried out in a hermetically closed container. The density, hiding power and color characteristics of the obtained nail polish samples were evaluated by painting the samples on white coated cardboard. Further research of nail polish toxicity, allergenicity and storage stability are required.

Emulsions were prepared in following wayweighed portions of oil and the Tween-80 emulsifier previously taken on a laboratory scale were dispersed using a pestle, and purified water was gradually added. The active components in the emulsion were introduced according to the principle of similarity: fat-soluble, lipophilic - in the oil phase, watersoluble - in the aqueous phase. The resulting emulsions were packed in dark glass bottles with a volume of 10 and $15 \mathrm{ml}$ with a screw cap and a built-in pipette, labeled and placed in storage. The quality of the obtained emulsion samples was evaluated in accordance with the requirements of the General Pharmacopoeia Monograph. 1.4.1.0017.15 Emulsions. The resulting emulsion was a homogeneous liquid, from milky white to yellowish in color, with no visible signs of phase separation during storage and without a pronounced odor. During the study, the most appropriate combinations of components for the emulsion were determined. Two compositions were developed: to maximize the acceleration of regeneration and the growth of a healthy nail plate and improving trophic innervation (Table 3).

Table 3. The composition of the experimental samples of emulsions.

\begin{tabular}{|l|c|c|c|c|}
\hline \multirow{2}{*}{ Component name } & \multicolumn{2}{|c|}{ Sample 1 } & \multicolumn{2}{c|}{ Sample 2 } \\
\cline { 2 - 5 } & mass, $\boldsymbol{g}$ & $\mathbf{\% ,} \boldsymbol{m}$ & mass, $\boldsymbol{g}$ & $\mathbf{\% ,} \boldsymbol{m}$ \\
\hline $\begin{array}{l}\text { Oil phase (forming component } \\
\text { according to SP 13) }\end{array}$ & 2,0 & 10,00 & 2,0 & 10,00 \\
\hline Aqueous phase (purified water) & 16,0 & 80,00 & 15,5 & 77,50 \\
\hline Emulsifier (Tween-80) & 1,0 & 5,00 & 1,0 & 5,00 \\
\hline $\begin{array}{l}\text { Components that enhance } \\
\text { regeneration and stimulate the } \\
\text { growth of the nail plate (total) }\end{array}$ & 0,5 & 2,5 & - & - \\
\hline
\end{tabular}




\begin{tabular}{|l|c|c|c|c|}
\hline $\begin{array}{l}\text { Components that improve } \\
\text { microcirculation (total) }\end{array}$ & - & - & 1,0 & 5,00 \\
\hline Liquid food flavoring & 0,5 & 2,5 & 0,5 & 2,5 \\
\hline Total mass & 20,0 & 100,00 & 20,0 & 100,00 \\
\hline
\end{tabular}

Emulsion samples which were obtained in laboratory conditions were analyzed by several parametrs for compliance with the requirements that are written in normative documents. Table №4 shows analysis results.

Table 4. The results of the prototypes analysis.

\begin{tabular}{|c|c|c|c|}
\hline $\begin{array}{c}\text { Analyzed } \\
\text { parameter }\end{array}$ & $\begin{array}{c}\text { Regulatory } \\
\text { requirement }\end{array}$ & Sample 1 & Sample 2 \\
\hline \multirow[t]{3}{*}{ Description } & $\begin{array}{l}\text { It should be a } \\
\text { homogeneous liquid in } \\
\text { which delamination } \\
\text { disappears after shaking }\end{array}$ & $\begin{array}{l}\text { Homogeneous } \\
\text { liquid without } \\
\text { visible signs of } \\
\text { separation during } \\
\text { storage }\end{array}$ & $\begin{array}{l}\text { Homogeneous } \\
\text { liquid with slight } \\
\text { signs of phase } \\
\text { separation, } \\
\text { disappearing with } \\
\text { shaking for } 30 \\
\text { seconds }\end{array}$ \\
\hline & Colour & $\begin{array}{l}\text { Liquid from } \\
\text { milky white to } \\
\text { milky white with } \\
\text { a yellowish } \\
\text { colour }\end{array}$ & $\begin{array}{l}\text { Liquid from milky } \\
\text { white to milky } \\
\text { white with a } \\
\text { pinkish colour }\end{array}$ \\
\hline & Odor & \multicolumn{2}{|c|}{ Matches the used flavor } \\
\hline Packaging & $\begin{array}{l}\text { Single or multi-dose } \\
\text { packaging, equipped, if } \\
\text { necessary, with a device } \\
\text { that provides ease of } \\
\text { use and dosage of the } \\
\text { drug }\end{array}$ & \multicolumn{2}{|c|}{$\begin{array}{l}\text { Multi-dose packaging - a glass bottle of } \\
\text { dark glass with a screw cap and a built- } \\
\text { in dispensing device - a glass pipette } \\
\text { that provides the dosage of the drug } \\
\text { with drops }\end{array}$} \\
\hline
\end{tabular}

Assessment of the organoleptic properties of the proposed compositions was carried out by a group of independent experts of 20 people. Experts were asked to evaluate the property of the proposed sample in several parameters, using a scale from 0 to 4 , where 0 the property is not expressed / not satisfactory / absent, 4 - the property is strongly pronounced / excellent. The results are presented in table 5.

Table 5. The results of the organoleptic properties assessment.

\begin{tabular}{|c|c|c|c|c|c|c|c|c|c|c|c|c|}
\hline \multirow{3}{*}{$\begin{array}{l}\text { Estimated } \\
\text { parameter }\end{array}$} & \multicolumn{5}{|c|}{$\begin{array}{c}\text { Number of experts } \\
\text { (Sample 1) }\end{array}$} & \multirow{3}{*}{$\begin{array}{c}\text { Average } \\
\text { rating } \\
\text { (Sample 1) }\end{array}$} & \multicolumn{5}{|c|}{$\begin{array}{l}\text { Number of experts } \\
\text { (Sample 2) }\end{array}$} & \multirow{3}{*}{$\begin{array}{c}\text { Average } \\
\text { rating } \\
\text { (Sample 2) }\end{array}$} \\
\hline & \multicolumn{5}{|c|}{ Rating } & & \multicolumn{5}{|c|}{ Rating } & \\
\hline & 0 & 1 & 2 & 3 & 4 & & 0 & 1 & 2 & 3 & 4 & \\
\hline Colour & 0 & 0 & 3 & 15 & 2 & 2,95 & 0 & 1 & 4 & 14 & 1 & 2,75 \\
\hline Odor & 0 & 1 & 4 & 10 & 6 & 3,15 & 0 & 2 & 3 & 12 & 3 & 2,80 \\
\hline $\begin{array}{l}\text { Packing } \\
\text { exterior }\end{array}$ & 0 & 0 & 2 & 3 & 15 & 3,65 & 0 & 0 & 2 & 3 & 15 & 3,65 \\
\hline $\begin{array}{l}\text { Convenience } \\
\text { of dosing }\end{array}$ & 1 & 3 & 2 & 4 & 10 & 2,95 & 0 & 2 & 2 & 10 & 6 & 3,00 \\
\hline
\end{tabular}


As we can see from table 5, expert estimates on the proposed parameters of two emulsion samples differ slightly. The composition and production technology of emulsions made possible to ensure the fastest delivery of compositions to patients with onychodystrophy due to the manufacture of an emulsion in the compounding pharmacy by prescription. The emulsion was prescribed to patients for 1 month, with a frequency of use of 1 time per day, applied to the periungual roller, and did not require subsequent removal from the nail apparatus. None of the patients reported side effects as a result of treatment. After 1 month of treatment and after 3 months, the patients were re-evaluated Dermatological Life Quality Index (Table 6).

Table 6. DLQI score in patients with onychodystrophies after 1 month of treatment and after 3 months $(n=76)$

\begin{tabular}{|l|c|c|c|c|}
\hline \multirow{2}{*}{ DLQI score } & \multicolumn{2}{|c|}{ After 1 month of treatment } & \multicolumn{2}{c|}{ After 3 months } \\
\cline { 2 - 5 } & Male & Female & Male & Female \\
\hline Very much & $8 / 10,5 \%$ & $18 / 23,7 \%$ & $2 / 2,6 \%$ & $4 / 5,3 \%$ \\
\hline A lot & $14 / 18,4 \%$ & $14 / 18,4 \%$ & $4 / 5,3 \%$ & $3 / 3,9 \%$ \\
\hline A little & $9 / 11,8 \%$ & $11 / 14,5 \%$ & $14 / 18,4 \%$ & $24 / 31,6 \%$ \\
\hline Not at all & $2 / 2,6 \%$ & $0 / 0$ & $13 / 17,1 \%$ & $12 / 15,8 \%$ \\
\hline
\end{tabular}

After a repeated study of DLQI (1 month of treatment) an improvement in the life quality was noted by $9(15.8 \%)$ patients, when the growth of healthy nail plates by $3-4 \mathrm{~mm}$ was clinically observed. After 3 months, 53 patients $(82.9 \%)$ noted a significant improvement in the life quality, and the growth of the nail plates averaged $8 \pm 2 \mathrm{~mm}$.

\section{Conclusion}

The developed innovative bioactive complex for patients with local pathological processes in the nail plate is an effective method for topical treatment of this pathology, and the emulsion will contribute to faster recovery of the alterated nail plate due to improved microcirculation, trophic innervation and stimulation of regeneration processes, which will improve the life quality of patients with onychodystrophies.

\section{References}

1. A.Yu. Sergeyev, Fungal disease of the nails (Moscow, 2001)

2. A.A. Tsykin, N.S. Sirmays, Russian Medical Journal, 9, 508 (2015)

3. A.N. Zorin, Advances in Medical Mycology, 15, 232-233 (2016)

4. M.M. Tlish, Onikhodistrofii (Krasnodar, 2013)

5. Ye.I. Kasikhina, Advances in Medical Mycology, 14, 88-90 (2015)

6. S.R. Lipner, R.K. Scher, JAMA, 316(18), 1915-1916 (2016)

7. T. Oppel, H.C. Korting, Ger. Med. Sci.., 1, Doc02 (2003)

8. T. Pinteala, A.E. Chiriac, I. Rosca, F. Larese Filon, M. Pinteala, A. Chiriac, C. Podoleanu, S. Stolnicu, M.F. Coros, A. Coroaba Skin Appendage Disord, 2(3-4), 137-142 (2017)

9. M.M. Simoes Mendonca, C. LaSenna, A. Tosti Skin Appendage Disord., 1(2), 91-94 (2015)

10. K.I. Al-Hamdi, D.K. Ismael, A.Q. Saadoon, Skin Appendage Disord., 5(4), 379-382 (2019)

11. F.M. Damasco, L.J. Geskin, O.E. Akilov, J. Cutan. Med. Surg., 23(4), 380-387 (2019)

12. U. Wollina, Skin Appendage Disord., 3, 4, 188-189 (2017) 
13. A.W. Stern, J. Pieper, J. Am. Vet. Med. Assoc., 246, 2, 197-199 (2015)

14. R.L. Prayogo, G. Rahmayunita, T. Agustin, S.P. Sirait, R. Arisanty Pediatr Dermatol, 37, 1, 180-183 (2020)

15. G. Moreno-Coutiño, R. Fernández-Martínez, E.C. Sánchez-Moreno, A. LozanoPlatonoff, C. Rodríguez-Salinas, A. Rosas-González, C.A. Sánchez-Mojica, R. Arenas, J. Vasc. Nurs., 34, 1, 24-26 (2016)

16. A.A. Shakhnovich, N.B. Korchazhkina, Kremlin Medicine Journal, 1, 40-44 (2018)

17. M. Warshaw, C.A. Traywick, A.A. Hoffman, K.K. Lilly, R.L. Koshnick, J.W. Robinson, P. Suwattee, J.K. Foster, Mycoses, 51(1), 14-20 (2008)

18. D. Ho Successful, A. Mamalis, J. Jagdeo, J. Drugs Dermatol., 15(11), 1461-1464 (2016)

19. F. Cantoresi, M. Caserini, A. Bidoli F. Maggio, R. Marino, C. Carnevale, P. Sorgi, Clin. Cosmet. Investig. Dermatol., 7, 185-190 (2014)

20. A. Chiavetta, S. Mazzurco, M.P. Secolo Dermatol, Ther., 32(5), 13028 (2019) 